\title{
TABLERO DE ALTAR Y ELEMENTOS CONSTRUCTIVOS TARDOANTIGUOS DEL YACIMIENTO DE NUESTRA SEÑORA DEL BUEN SUCESO, TÉRMINO MUNICIPAL DE AZNALCÓLLAR (SEVILLA)
}

\author{
LATE ANTIQUITY ALTAR BOARD AND RESERVOIR CONSTRUCTIVE ELEMENTS FROM THE \\ NUESTRA SEÑORA DEL BUEN SUCESO SITE, MUNICIPALITY OF AZNALCÓLLAR (SEVILLA)
}

\author{
MARK A. HUNT ORTIZ* \\ ISAAC SASTRE DE DIEGO**
}

\begin{abstract}
Resumen: Durante el proceso de excavación del yacimiento de Nuestra Señora del Buen Suceso, Aznalcóllar (Sevilla), fueron documentados restos correspondientes a diversas fases de ocupación, desde época romana a la actualidad. Integrado en un edificio del siglo XVII d.C. se recuperó un fragmento de mármol que se ha identificado como tablero de altar, con una cronología entre los siglos V y VII d.C. La revisión del registro arqueológico ha permitido identificar, encontrados también en contextos modernos, otros elementos constructivos de la misma cronología.
\end{abstract}

Palabras clave: Arqueología, Aznalcóllar, tardoantiguo, altar, elementos constructivos

\section{INTRODUCCIÓN}

El descubrimiento en el coto minero de Aznalcóllar de una nueva masa de pirita compleja, cuya explotación mediante corta a cielo abierto resultaba rentable, hizo que la compañía minera Boliden-Apirsa, S.L., patrocinara, en el ámbito de los estudios de impacto medioambiental, la prospección arqueológica superficial de los terrenos que podrían verse afectados por la futura mina.

\footnotetext{
* Grupo de Investigación “Atlas” (HUM-694), Dep. de Prehistoria y Arqueología, Universidad de Sevilla

** Instituto de Arqueología de Mérida (CSIC-Junta de Extremadura-Consorcio de Mérida).
}

Abstract: During the archaeological excavation of the site Nuestra Señora del Buen Suceso (Aznalcóllar, Sevilla), elements corresponding to various phases of occupation, from Roman times to present times, were documented. Integrated in a 17 th. century AD building, a marble fragment was recovered, identified as an altar panel, with a chronology between the 5 th. and 7 th. centuries AD. The revision of the archaeological record of the excavaction has allowed the identification, also found in Modern contexts, of other constructive elements of the same chronology.

Key words: Archeology, Aznalcóllar, late antiquity, altar, constructive elements

La prospección se realizó en 1992 y, como uno de los resultados, se localizó el yacimiento que fue denominado en primera instancia "Convento" (Hunt Ortiz 1995), cuyos restos, tras la investigación archivística llevada a cabo, pudieron ser identificados como correspondientes al antiguo monasterio de Nuestra Señora del Buen Suceso del Retamal, fundación del Conde-Duque de Olivares (también conde de Aznalcóllar) de la primera mitad del siglo XVII d.C. (Hunt Ortiz 1999).

Una vez delimitado el yacimiento, al situarse en el área de afección directa por la futura corta minera, en 1993/1994 se procedió a su excavación de urgencia, que también fue financiada por la misma compañía minera (Hunt Ortiz 1999). 


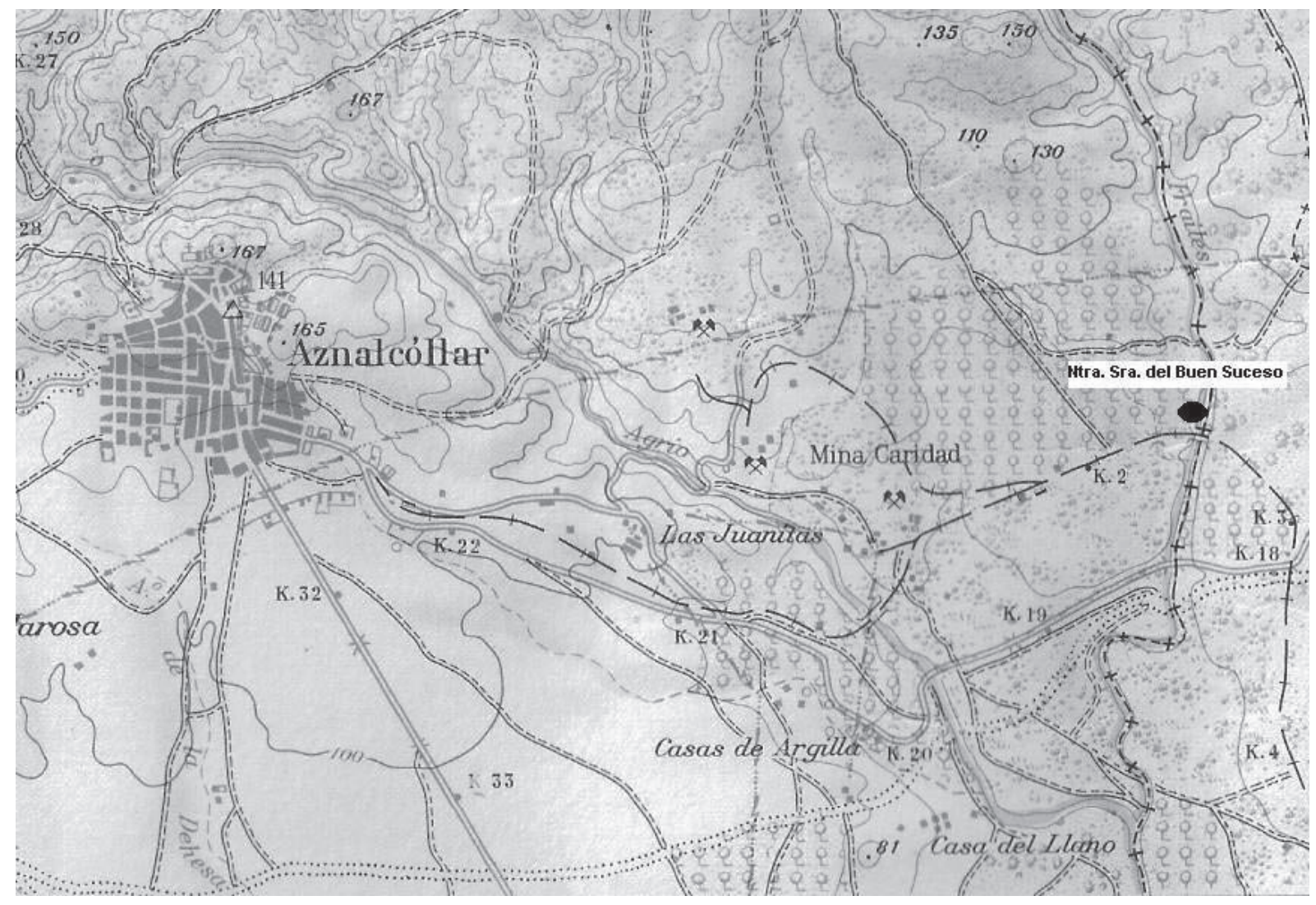

Figura 1: Localización Monasterio de Nuestra Señora del Buen Suceso. Hoja 961 (Aznalcóllar) del Mapa del Instituto Geográfico y Catastral. E:1/50.000. Año 1966.

\section{SITUACIÓN DEL YACIMIENTO Y CONTEXTOS DE LOS ELEMENTOS MUEBLES}

El yacimiento de Nuestra Señora del Buen Suceso se sitúa $4 \mathrm{kms}$. al Este de la población de Aznalcóllar (parte central-oeste de la provincia de Sevilla), en el límite del término municipal, constituido en esa zona por el cauce del arroyo Los Frailes (Fig. 1)

Para la situación del yacimiento se ha utilizado intencionadamente planimetría antigua, ya que en la década de 1970 se modificó sustancialmente todo ese territorio al realizarse una primera corta a cielo abierto, denominada corta "Aznalcóllar". En la actualidad, la realización de la nueva corta minera "Los Frailes" ha conllevado que la mayor parte de la superficie del yacimiento haya desaparecido, conservándose sólo la más cercana al arroyo Los Frailes, que incluye el molino y los antiguos baños del Pradillo del Tardón (Hunt Ortiz 2000).

En la intervención arqueológica de urgencia llevada a cabo (Hunt Ortiz 1999) fueron excavados los restos correspondientes a las diferentes edificaciones y estructuras productivas del monasterio de Nuestra Señora del Buen Suceso del Retamal (edificio principal con necrópolis asociada-, almazara, noria y, en el río de los Frailes, un molino) (Fig. 2).

Además de la ocupación monacal, que se prolongó hasta el inicio del siglo XIX d.C., se documentaron restos correspondientes a épocas romana e islámica. De época romana se distinguieron dos fases de ocupación (Hunt Ortiz 1999: 453-4): una de época altoimperial, con cremaciones y restos de estructuras hidráulicas y una posterior, del siglo IV d.C., a la que se asocian restos de amplias estructuras murarias y un área funeraria de inhumaciones. En el límite NO de la zona de intervención-Cuadrícula 6- (Fig. 2), se documentó un conjunto de restos de estructuras murarias que se consideraron posiblemente de época romana por su factura, aunque todas muy destruidas, conservándose en el mejor de los casos alguna hilada de las cimentaciones (Hunt Ortiz 1999: 454).

También se señaló la detección de materiales reaprovechados o encontrados fuera de contexto, que parecían 


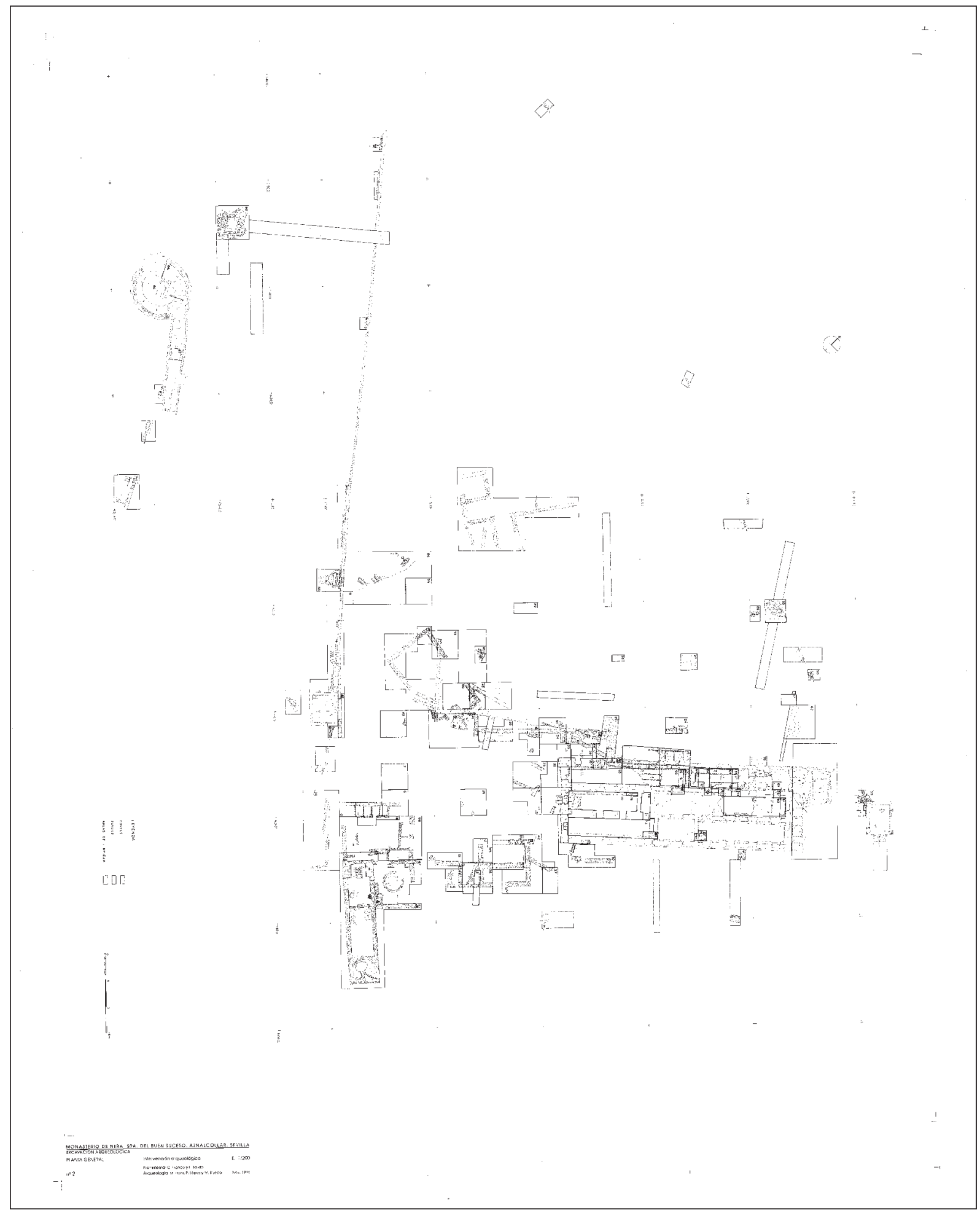

Figura 2: Monasterio de Nuestra Señora del Buen Suceso. Aznalcóllar (Sevilla). Excavación Arqueológica. Planta General. 


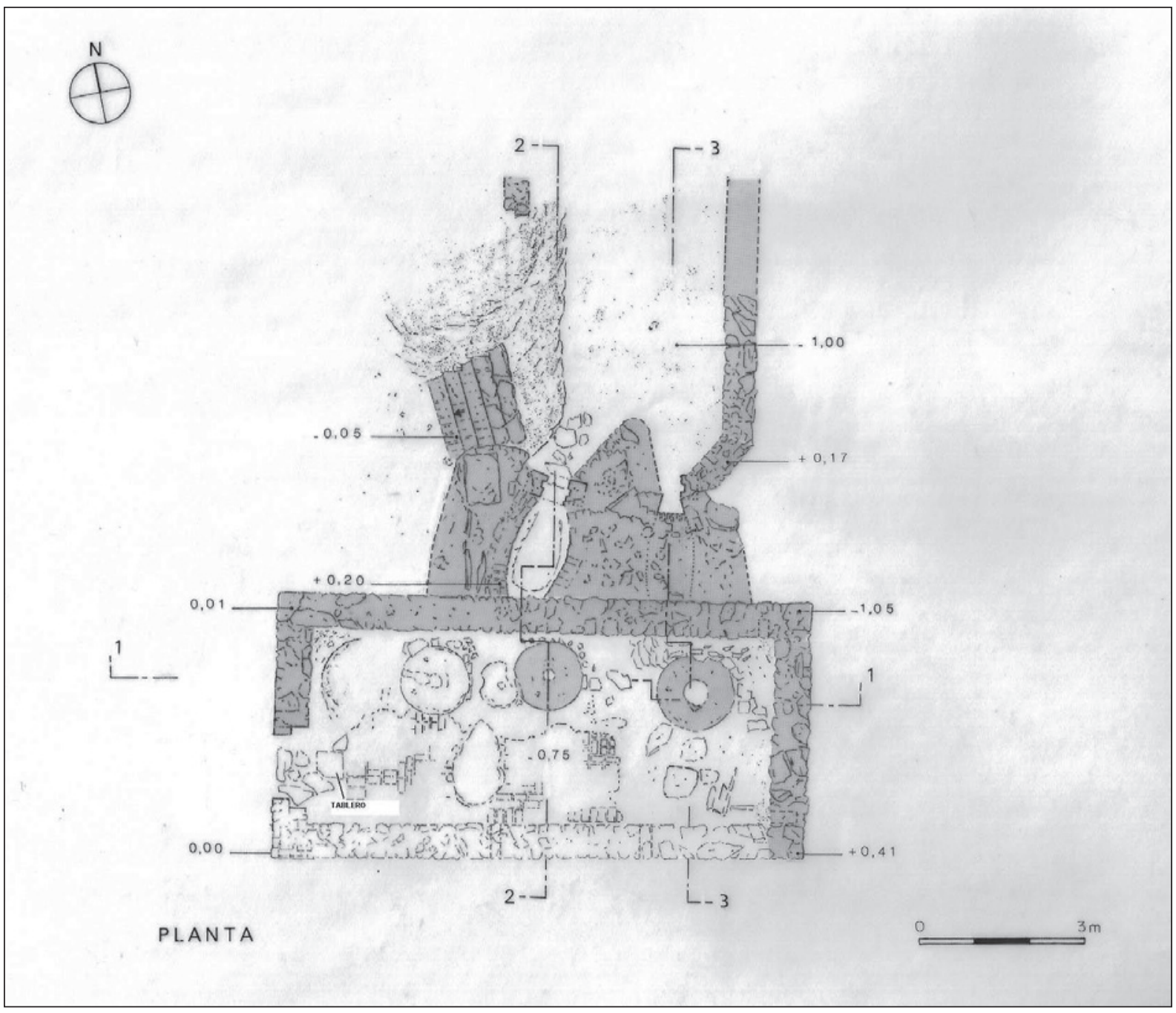

Figura 3: Monasterio de Nuestra Señora del Buen Suceso. Aznalcóllar (Sevilla). Excavación Arqueológica. Planta del Molino Monacal.

corresponder a época visigótica: un capitel y un fragmento de altar, ambos de mármol, y varios fragmentos de ladrillos decorados. Concretamente, reutilizada en el suelo del molino monacal (Fig. 3), en cuya fábrica también se reaprovecharon otros elementos constructivos de épocas anteriores como ladrillos de módulo romano, se recuperó el elemento que fue clasificado como un posible fragmento de tablero de altar de mármol (Ref. AZ94-C47) (Hunt Ortiz 1999: 454) (Fig. 4).

La "losa" de mármol estaba dispuesta del revés, con la decoración oculta (Fig. 5) y fragmentada, siendo necesaria su posterior restauración.

El capitel de mármol (Ref. AZ-94-W Noria-S/C) (Fig. 6; Fig. 7), fue encontrado en el límite Oeste de la zona de intervención en la zona de huertas, formando parte del derrumbe de un tramo de la pared de la rampa de acceso a la noria monacal (Fig. 2).

Finalmente, fueron documentados durante la intervención arqueológica 2 ladrillos decorados fragmentados: el denominado AZ-94-SC (Fig. 8), recogido en superficie, y el AZ-94-C86-2493 (Fig. 9), que se excavó en niveles modernos en el ámbito del Corte 86 (Fig. 2).

\section{EL TABLERO DE ALTAR (FIG 4; FIG. 5 A-B): CARACTERÍSTICAS Y PARALELOS}

La pieza fue realizada en mármol blanco y se conserva de forma incompleta $(50 \times 40 \times 5 \mathrm{~cm}$.), que correspondería a algo menos de la mitad de lo que sería su 


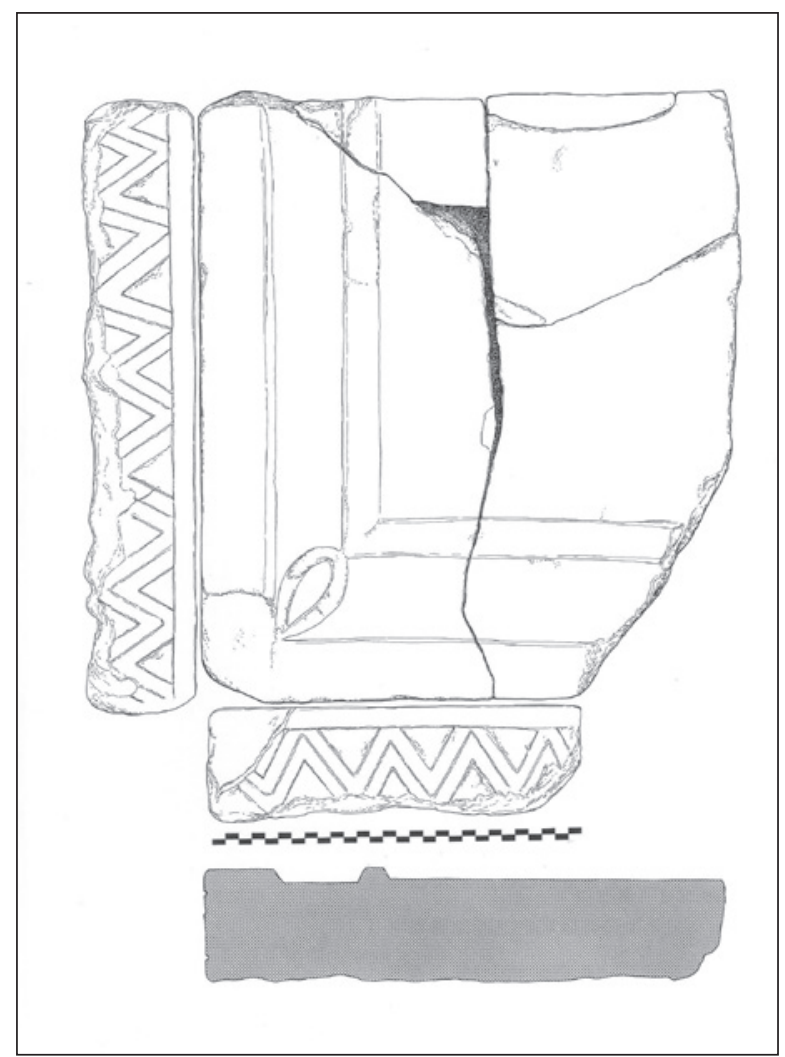

Figura 4. Fragmento de tablero de altar de mármol (AZ-94-C47)

forma rectangular original. El plano superior dispone de un marco compuesto por dos molduras rectas separadas con bordes en talud, una moldura exterior más ancha y otra interior menor, cuyas aristas quedan unidas por una hoja lanceolada de contorno biselado; esta composición apenas sobresale del plano central o campo litúrgico, que queda liso y a una cota ligeramente inferior. El canto, vertical, posee una decoración geométrica: un doble zig-zag enmarcado horizontalmente por listeles, aunque se conserva únicamente el superior, quedando insinuado el inferior, ya que la pieza presenta varias roturas en esa parte. La decoración es la misma en los dos frentes conocidos del canto del tablero, por lo que suponemos que el zig-zag recorría los cuatro frentes, aunque no debe descartarse que en el centro del lado mayor se insertara un motivo diferenciado alusivo a su función litúrgica.

El ejemplar de Aznalcóllar formaría parte del grupo hispánico de tableros de altar cristianos de tradición romana (Sastre de Diego 2009), caracterizados por ser placas rectangulares que conservan la tradición
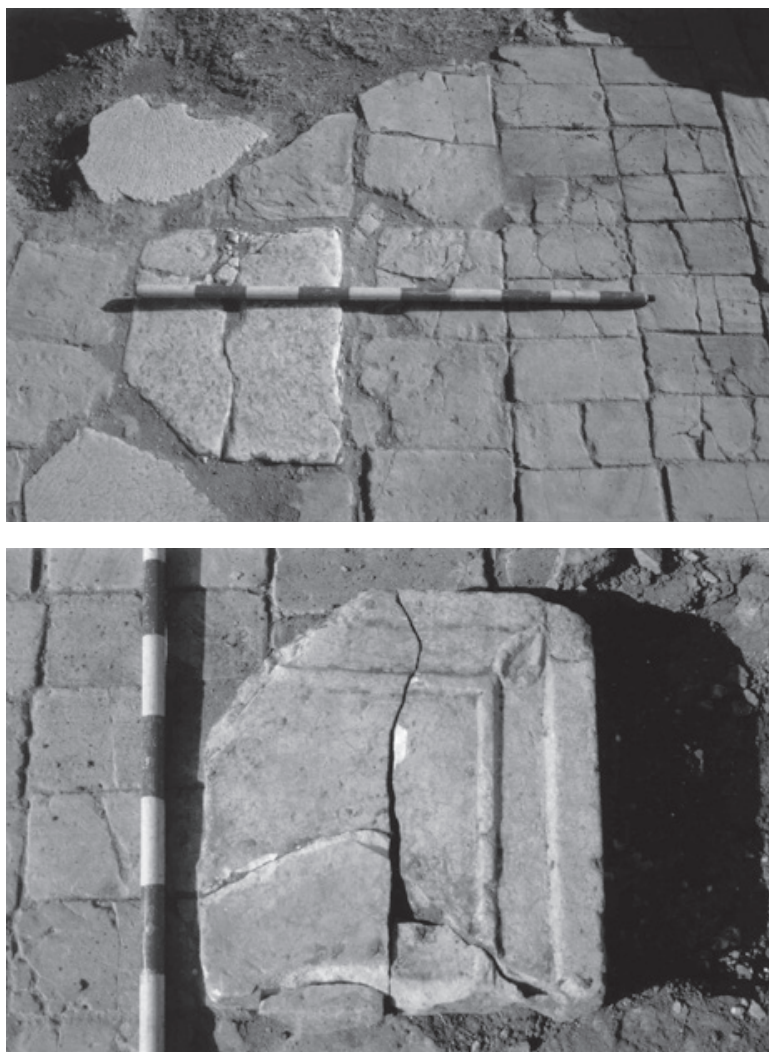

Figura 5. Tablero de altar de mármol (Ref. AZ-94-C47). Ia: Posición en la que fue documentado. Ib: Anverso en el momento de su excavación.

de la cyma inversa, destacándose el borde mediante un marco de triple moldura. Esta es la zona donde se concentra la ornamentación que pueda haber, a la vez que se enmarca el campo litúrgico. En este tipo de tableros el canto es vertical o ligeramente inclinado hacia el interior, y se caracteriza por su poco grosor, entre los 4 y $10 \mathrm{~cm}$., aunque suelen presentar grandes dimensiones, superando los de mayor tamaño el metro de longitud, como los ejemplares catalanes (Ampurias, Santa María de Tarrasa, San Pedro de Tarrasa, seguramente Vic, etc.) (Alavedra 1979), los de Casa Herrera en Mérida (Caballero y Ulbert 1976) y los del santuario de El Trampal en Cáceres (Caballero y Sáez 1999), cuyos perímetros totales $(1,80 \times 1,07 \mathrm{~m}$ y $1,65 \times 1,15 \mathrm{~m}$ respectivamente) son conocidos por las huellas del ara y de los soportes. Estos tableros conforman una de las tipologías de altar más empleadas en la Hispania tardoantigua y altomedieval: mesas de altar rectangulares cuyo tablero es sostenido por cuatro soportes, columnitas o pilastrillas, colocados en las esquinas, y el ara, de mayores dimensiones que estos, situada en el centro. 


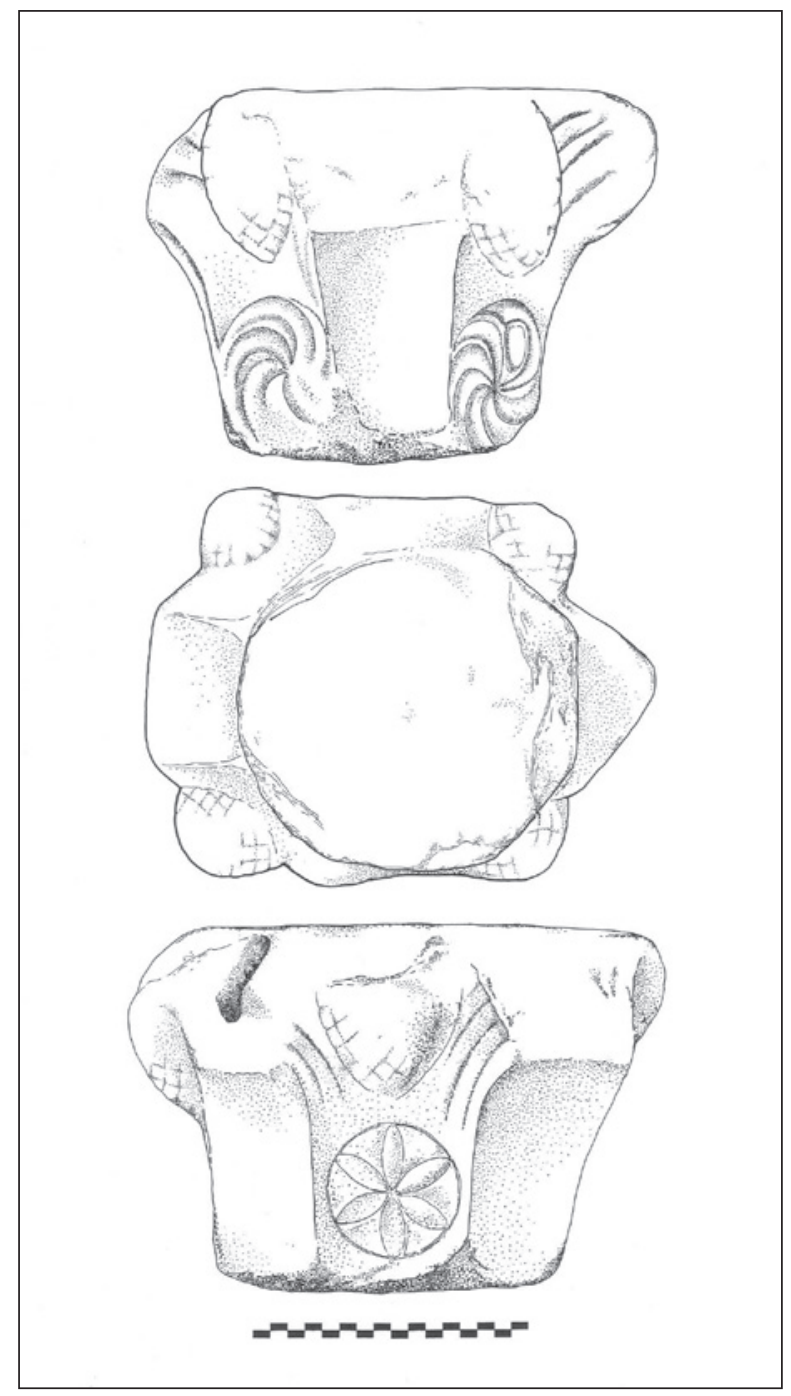

Figura 6. Capitel decorado de mármol (AZ-94-W Noria- S/C).

Dentro del tipo, se han diferenciado dos variantes o subgrupos: en la primera variante los tableros presentan una continuidad directa con las formas romanas, incluso con reutilización directa. La segunda variante se caracteriza por la modificación del marco, que tiende a su esquematización a través de una moldura de tipo gola que establece el descenso de cota entre el borde y el campo litúrgico, como en el tablero recientemente hallado de Carteia ${ }^{1}$, elemento que también remonta su origen a la producción de las placas romanas.

1. Agradecemos al equipo de investigación de Carteia, en especial al Dr. M. Bendala, la información proporcionada sobre esta pieza, catalogada con la identificación AND2 (Sastre de Diego 2009).

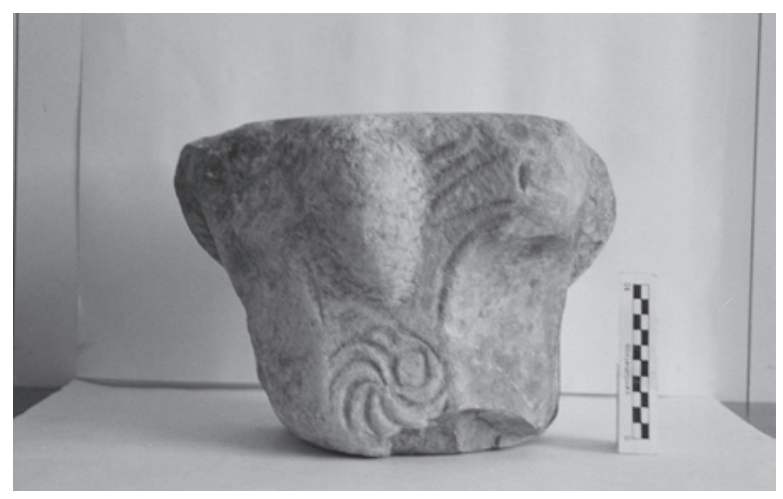

Figura 7. Capitel de mármol (AZ-94-W Noria- S/C).

Otra fórmula también empleada es la composición del marco en una doble moldura, más ancha junto al borde y más fina al interior, como sería la empleada en el tablero de Aznalcóllar, soliéndose aprovechar las aristas generadas en la unión de ambas molduras para incluir alguna decoración, como la hoja lanceolada presente en el de Aznalcóllar.

En el caso tablero depositado en el Museo de Córdoba, de tradición de cyma inversa, una hoja acorazonada une las aristas de las dos primeras molduras (Hidalgo 2000: 741-754; Sánchez 2006: 70, nº 82; Sastre de Diego 2009 AND18).

Hay que mencionar que existen casos en los que se utiliza una tercera fórmula para crear la separación entre borde y plano central, mediante la esquematización de la moldura de gola, diferenciándose el marco y campo litúrgico mediante corte recto, como es el caso de la iglesia de Alconetar, en Cáceres, o por un sencillo talud, caso de uno de los tableros procedentes de Santa Eulalia de Mérida (Mateos 1999).

Por otra parte, la mayor profusión decorativa de la zona del borde es un rasgo identificativo de algunos tableros de altar de la Bética. Así, en el dibujo conservado del tablero, perdido, de Salpensa, Sevilla, tras las molduras clásicas del marco también unidas por hojas en las aristas, una tercera moldura aparece decorada con motivos vegetales, roleos que recorren los cuatro lados, mientras que la inscripción dedicatoria del obispo Pimenio (ca. 648 d.C.) recorrería el canto, de la misma manera que ocurre en el tablero de Baza, Granada (Caballero et al., 2006).

Por otra parte, también es destacable la decoración del tablero de Almonaster (Huelva), que se distribuye tanto en el marco como en el canto. En este caso a la composición vegetal se le suman otros elementos figurativos, ángeles y palomas, con rasgos esquemáticos y utilizando la técnica de las líneas paralelas para llenar 


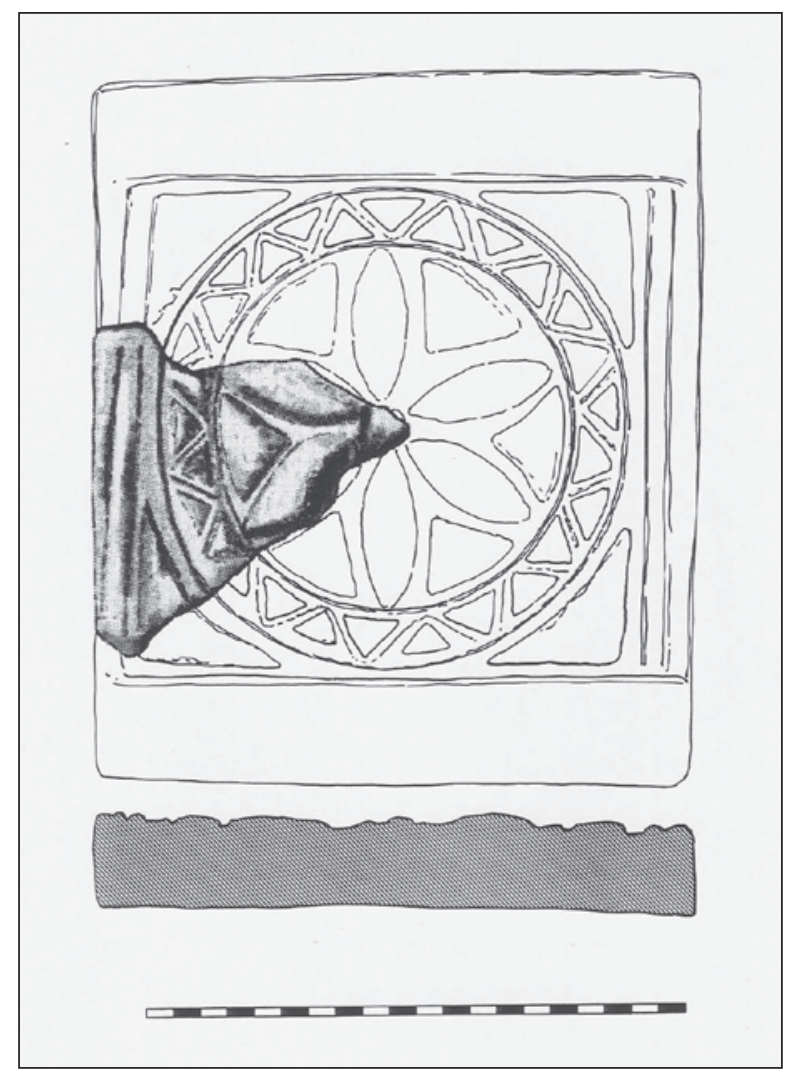

Figura 8. Fragmento de ladrillo decorado (AZ-94-SC)

el interior de los volúmenes (Jiménez Martín, 1975; Sastre de Diego, 2009: 207).

Mayor relación estilística en la composición respecto al ejemplar de Aznalcóllar se da en el tablero de Alcaudete (Jaén), donde la geometría cubre todo el plano superior además del borde, creando, a base nuevamente de líneas paralelas, roleos para el canto, ondas para el marco y una gran cruz patada en el campo litúrgico (Sastre de Diego 2009: 208-209).

\section{CONTEXTUALIZACIÓN FUNCIONAL E HISTÓRICA DEL TABLERO DE ALTAR DE AZNALCÓLLAR}

Como suele ser habitual respecto al mobiliario litúrgico tardoantiguo y altomedieval, se desconoce el contexto originario de esta pieza, que se excavó, como se ha indicado, formando parte del enlosado interior de una dependencia monacal. Sus características formales, de composición, ejecución técnica del marco y el grosor, la encuadran en el grupo de tableros de altar de época tardoantigua, con una cronología general comprendida

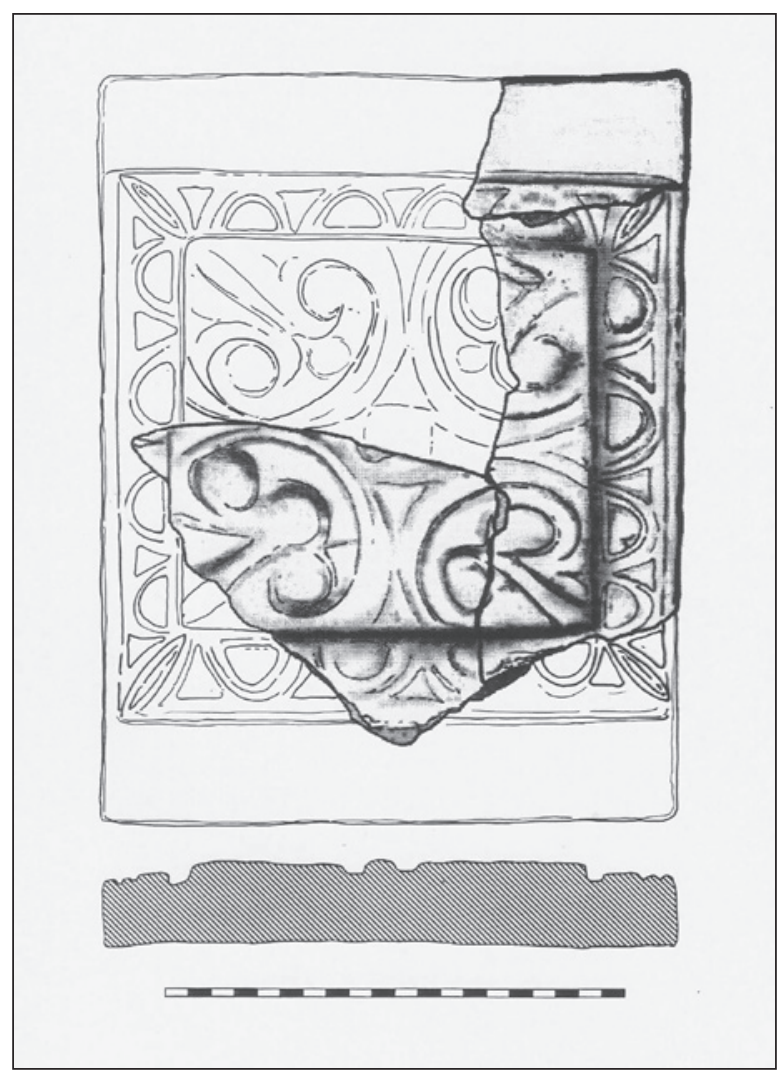

Figura 9. Fragmentos del ladrillo decorado (AZ-94-C86-2493)

entre los siglos V y VII d.C., aunque con perduraciones esporádicas. Los ejemplares más antiguos corresponderían a los englobados en la primera variante, mientras que los agrupados en la segunda variante, en los que se incluiría el tablero de Aznalcóllar, se acercarían más al siglo VII d.C. Así, el tablero de Baza, con una composición del marco similar, también esquematizada, por la inscripción conservada en su canto (---)bivs aepiscopus omniv(m)(---) se relaciona con el obispo Eusebio de la sede bastetana, encuadrándose, por tanto, en un ámbito cronológico situado en el segundo cuarto del siglo VII d.C., probablemente entre los años 633 y 638 (Caballero et al. 2006).

También puede compararse con el marco del tablero hallado en la basílica de Valdecebadar, Badajoz, que se data entre finales del siglo VI e inicios del siglo VII d.C. (Ulbert y Eger 2006). Por su parte, el tablero hallado por Íñiguez Almech (1955) en las excavaciones del exterior de Quintanilla de Las Viñas, en Burgos, sería uno de los ejemplares con cronología más reciente, muestra de la mencionada esporádica pervivencia de la segunda variante en la alta Edad Media. En él aparecen nuevas características que denotan su modernidad, 
como es el empleo de la caliza rosácea local en lugar del mármol blanco, material que había sido predominante en el grupo tardoantiguo.

\section{ELEMENTOS CONSTRUCTIVOS TARDOANTIGUOS DOCUMENTADOS EN EL YACIMIENTO}

Aunque el contexto en el que se excavó el tablero de altar (reutilizado en el siglo XVII d.C. como elemento constructivo) no es el suyo originario, es significativa la aparición en el mismo ámbito del yacimiento de elementos arquitectónicos que, también recuperados fuera de su contexto original, se adscriben a la misma cronología. Se trata, como ya se ha indicado, de un capitel igualmente realizado en mármol blanco (Fig. 5; Fig. 7) y de dos ladrillos decorados (Fig. 8; Fig. 9), que presentan, al igual que en el caso del tablero de altar, decoraciones geométricas. En el caso del capitel, muestra un repertorio de motivos circulares, probablemente hechos a compás: ruedas solares y una rosa hexapétala inscrita en un círculo; los caulículos están totalmente esquematizados, pareciendo no concluida totalmente su talla. Estas características permiten proponer una datación en la Antigüedad Tardía, pero también debemos tener en cuenta que las formas geométricas son habituales en la decoración de algunos capiteles medievales.

Respecto a los ladrillos, como se ha indicado, se conservan fragmentos correspondientes a dos piezas distintas, que pueden incluirse en el grupo de decoraciones exclusivamente de carácter geométrico, establecido por Fariña Couto (1939) en contraposición con el grupo de decoraciones figuradas. Palol (1961) también individualizó la ornamentación geométrica como un tema propio y definidor de un tipo o grupo de ladrillos. En uno de los ladrillos (AZ-94 SC) el motivo principal es, como en el capitel, una rosa hexapétala inscrita en un círculo decorado en zig-zag, el círculo a su vez se inscribe en un cuadrado. Por su parte, el otro ladrillo (AZ-C86-2493) presenta un cuadrado inscrito en otro cuadrado, con todo el espacio existente entre ambos rellenado con un friso de arquillos. En el cuadrado interior se desarrolla el motivo central: cuatro hojas de doble roleo vuelto hacia dentro, que surgen de los ángulos y se unen en el centro, generando una especie de cruz. La composición es similar a los ladrillos fabricados en serie de Lebrija, Sevilla, aunque sin la rueda central de estos (Caro Bellido 2003-2004). Las decoraciones de los ladrillos de Aznalcóllar también se asemejan a algunos de los que conforman la colección Olhonoz, hallazgos casuales procedentes de distintos puntos de las provincias de Sevilla, Córdoba y Huelva (Castello Ruano 1996) ${ }^{2}$. Los dos ladrillos documentados en este yacimiento de Aznalcóllar son de la tipología de bandas lisas o tabicas en los lados menores, flanqueando la decoración, que se limita al cuadrado central resultante. Caro Bellido (2003-2004) considera que la función de este tipo de piezas era la de decorar techos con vigas de madera, alternando entre estas, siendo posible que los motivos decorativos estuvieran pintados, como se desprende del pigmento rojo que conservaba uno de los ladrillos de Lebrija.

\section{CONSIDERACIONES GENERALES}

Aunque los elementos descritos recuperados en la excavación arqueológica llevada a cabo en el yacimiento de Nuestra Señora del Buen Suceso, Aznalcóllar (Sevilla), se encontraban dispersos en distintas zonas del área de intervención y fuera de su contexto original, sus características formales y funcionalidad permiten sugerir un origen común.

$\mathrm{Su}$ probable adscripción a un mismo grupo decorativo, eligiendo en todas las piezas similares composiciones geométricas, permite proponer su utilización primigenia en un mismo ámbito de carácter religioso, que se debería localizar geográficamente en un lugar relativamente próximo al yacimiento, y que cronológicamente se situaría en un momento muy avanzado de la Antigüedad Tardía.

\section{BIBLIOGRAFÍA}

ALAVEDRA, S. (1979): Les ares d'altar de San Pere de Terrassa, Egara. vol. I Les ares; vol. II Inventari de les ares. Terrassa.

CABALlERO, A.; GIMENO, H.; RAMÍREZ, M. y SASTRE DE DIEGO, I. (2006): "Tablero de altar de época tardoantigua hallado en Baza (Granada). ¿El primer documento epigráfico del obispo Eusebio?", Archivo Español de Arqueología 79: 287-292.

2. Castelo Ruano (1996) recoge en su catálogo de la colección Olhonoz los siguientes lugares dentro de la provincia de Sevilla donde se han encontrado ladrillos decorados: Herriza del Ciervo, Pedro Cruzado, El Rubio, Viso del Alcor, Morón de la Frontera y Cortijo de El Coronel. Se suman a los conocidos en Lebrija, Osuna, Alcalá del Río y Cortijo de Barbuán. No obstante, las mayores similitudes decorativas las encontramos con los ejemplares de "Cortijo de la Estrella”, en la provincia de Córdoba, y Torreón de Gerena, que es situado en la provincia de Huelva. 
CABALLERO, L. y SÁEZ, F. (1999): La iglesia mozárabe de Santa Lucía del Trampal, Alcuéscar (Cáceres), Memorias de Arqueología Extremeña 2.

CABALLERO, L. y ULBERT, T. (1976): La basílica paleocristiana de Casa Herrera en las cercanías de Mérida (Badajoz). Excavaciones Arqueológicas en España 89. Madrid.

CARO BELLIDO, A. (2003-2004): “A propósito de dos ladrillos visigóticos encontrados en la Bética", Estudios sobre patrimonio, cultura y ciencia medievales V-VI: 21-35. Cádiz.

CASTELO RUANO, R. (1996): "Placas decoradas paleocristianas y visigodas de la colección Alonso (Écija, Sevilla)", Espacio, Tiempo y Forma, Serie II. Historia Antigua 9: 467-536.

FARIÑA COUTO, L. (1939): "Notas sobre los motivos ornamentales visigóticos. El ladrillo con relieves", Boletín del Seminario de Arte y Arqueología de Valladolid 6: 205 ss.

HIDALGO, R., 2000: "Sobre la cristianización de la topografía de la Córdoba tardoantigua: el caso del palacio de Cercadilla", Arqueología da Antiguedade na Península Ibérica. Actas 3 Congreso Arqueología Penínsular t. 4: 741-745.

HUNT ORTIZ, M.A. (1995): “Prospección Arqueológica Superficial de Urgencia: Coto Minero de Aznalcóllar (Sevilla)", Anuario Arqueológico de Andalucía 1992, vol. III: 640-652.

HUNT ORTIZ, M.A. (1999): “Excavación Arqueológica del Monasterio de Nuestra Señora del Buen Suceso del Retamal (Aznalcóllar, Sevilla)", Anuario Arqueológico de Andalucía 1994, vol. III: 449-461.

HUNT ORTIZ, M.A. (2000): "Patrimonio HistóricoGeológico: Los Baños del Pradillo del Tardón y su Relación con el Filón de Sulfuros Complejos "Los Frailes", en J.M. Mata Perelló y J. Mollfullera (eds.), Actas del Primer Simposio Ibérico sobre Geología y Termalismo: 187-201. Dirección General de Energía y Minas, Generalitat de Cataluña.

ÍÑIGUEZ ALMECH, F. (1955): Algunos problemas de las viejas iglesias españolas. Cuadernos de Trabajos de la Escuela Española de Historia y Arqueología. Roma.

JIMÉNEZ MARTÍN, A. (1975): La Mezquita de Almonaster. Diputación Provincial-IEO, Huelva.

MATEOS, P. (1999): La basílica de Santa Eulalia de Mérida. Arqueología y Urbanismo. Anejos de Archivo Español de Arqueología XIX. CSIC, Consorcio de la Ciudad Monumental de Mérida, Madrid.

PALOL, P. de (1961): "Placas en cerámica decoradas paleocristianas y visigodas", Scritti di Storia dell'Arte in onore di Mario Salmi: 13 ss. Roma.

SÁNCHEZ, J., (2006): Elementos arquitectónicos de época visigoda en el Museo Arqueológico de Córdoba. Arquitectura y Urbanismo en la Córdoba Visigoda, Series del Museo Arqueológico de Córdoba 1. Junta de Andalucía, Sevilla.

SASTRE DE DIEGO, I. (2005): "Los altares de Extremadura y su problemática (siglos V-IX)", Hortus Artium Medievalium 1: 97-110.

SASTRE DE DIEGO, I. (2009): El altar en la arquitectura cristiana hispánica. Siglos V-X. Estudio Arqueológico. Tesis doctoral, Universidad Autónoma de Madrid.

ULBERT, T. y EGER, Ch. (2006): "Valdecebadar bei Olivenza (Badajoz). Neue Untersuchungen in der Kreuzförmigen Kirche und ihrem Umfeld", $M a$ drider Mitteilungen 47: 221-252. 